\title{
The Depiction of Gender-Based Violence and Female Homicide in Public Discourse
}

\author{
Chatzifotiou Sevasti ${ }^{1}$, Kalfa Maria ${ }^{2}$ \\ ${ }^{1}$ Associate Professor of Social Work, Social Worker M.A., Democritus University of Thrace \\ ${ }^{2}$ Phd Candidate Political Science AUTH, Social Anthropologist, Gender Studies MSc, Multicultural \\ Education MSc, Management and Organization of Educational Units MSc, Social Policy in crisis situations MSc
}

\begin{abstract}
This research, attempts to investigate gender-based violence in public discourse. "Passion crimes", "jealousy", "honor" often describe in the journalistic discourse crimes of sexual violence, which deprive many women around the world of their lives. More specifically, according to recent UN data, on average, 137 women around the world are murdered daily by their partner or a relative. This research highlights issues of gender-based violence and how they are presented in public discourse. Reality is constructed through the way we choose to talk about this. The term homicide is used for the murders of women and girls, for murders committed because of their gender. This term became known to the general public after the latest incidents of gender-based violence in Greece that cost the lives of girls and women who were murdered solely because of their gender. This analysis may be oversimplifying for someone, but gender-based violence is slowly, almost silently, cultivating in Greek society and making noise when there are consequences.
\end{abstract}

Keywords: homicide, gender-based violence, Discourse, gender roles

\section{Introduction}

The purpose of this article is to point out issues related to the murder of women, to highlight issues related to the power that one has to exercise power and how this 'power' is cultivated by the direct and indirect environment. The family and wider social context teaches us to be 'resistant' to the expression of aggression and persistence of boys, forgetting that in this way the conditions for the legitimacy of the exercise of power (physical, etc.) are created. 'Come on baby boy' (in cases where they are aggressive), 'men do not cry', 'what are you crying like a woman' etc. are expressions that 'build' a toxic masculinity, where aggression and expression becomes' nature and a basis for legitimizing authoritarian and aggressive behaviors."What is female homicide?" It is the murder of a woman or a girl because of her gender according to the definition of the French dictionary PETIT ROBERT that included the term in the body of his words only in 2015 "(Petraki, 2020). 


\section{Public Discourse and Ideology: Constructing Inequality in Public Speech}

"Cultural Discourses construct dipoles, which categorize the abilities, inclinations and characteristics of the genders. "Since the 18th century, the notions of male 'energy' and female 'passivity' have been emerging" (Laqueur, 2003). Language itself is certainly not neutral, it is influenced by various circumstances and we seem to be called upon to adapt each time to whatever requirements the circumstances impose. Our language choices are determined by factors such as age - ours and our interlocutor -, gender, social class, context, social status, degree of closeness, etc. We would not dare to speak to our manager as we interact with our friend, but even this is not absolute, because it can change depending on proximity, intimacy, working conditions, years of cooperation, etc. "Together with social class, age, nationality, gender is one of the basic social parameters that is clearly linked to language choices" (Pavlidou, 2006). Language is a social phenomenon that is not neutral and is subject to evaluation. Through language activity, individuals define their identity based on the sociocultural contexts that surround them. Language users have to deal with both the gender nature of the language and the expectations of others on a linguistic level and beyond. Often, as Fragoudaki (1988) says, "sexist ideology exists in the words themselves and their meaning, in the use of language, in syntax in grammar [and while] grammatical detail is small, its semantic implications are big". "As Foucault point out, the Discourse is power, as the language we use to talk about a subject constructs the subject" (Kalfa, 2017). Can language be socially innocent? No, as it "comes to serve the various expediencies, to express social stratification, values, prejudices and infinite social determinations, containing and conveying numerous social and ideological information even with the simplest phrases" (TsitsanoudiMallidi, 2006). Through language, the power relations of society are reproduced, with the result that words carry an ideological burden and structure reality in a subjective way. The power relations established in society do not leave unaffected the words or those who use them. According to Tsitsanoudi-Mallidi (2008): "... journalistic discourse transmits not only explicit information, but also implicit (ideas, opinions, messages, perceptions)". According to Eco (2017), "the hypothesis of objectivity is part of the 'ideology' of modern journalism, but it must be clear that this is precisely an 'ideological' point of view". The words carry ideology, choosing to use the term murder, but not feminicide, we reject the power relations that have been established in a society as far as gender is concerned. The same happens when it comes to other forms of human life that can adversely affect some subjects due to nationality, sexuality, etc. Claiming the 'right' words is about visibility, the visibility of subjects, power relations and the willingness to reshape them.

Since the words used to talk about a subject make it up, it is worthwhile to look at the way female homicide is presented in the on line journalistic discourse. "News reports of rapes and murders of women tend to portray women as victims and those responsible for the victim blaming, while perpetrators are not part of the news and when they do appear, they are portrayed as their quiet people of the next door that no one had understood what they might be hiding "(Michalakeli, 2020). Something similar happens when it comes to female homicides, where while the perpetrator has shown signs of his violent behaviour, he is presented as a man 'beyond suspicion', a 'peaceful family man' and a man who 'never gave rights'. Remarkable is the study of Michalakeli, which shows how the female homicide is presented based on the political orientation of an information website. "A portion of the media adopt the term and contribute to its dissemination, including media that move in the broader left-center-left spectrum, international media that adopt the culture of political correctness of the Western 
world and have Greek publications and high-profile media. as a rule, conventional 'rounded' speech "(Michalakeli, 2020). "On the other hand, the use of the term is opposed by websites and blogs with neo-right and far-right space and individual authors of the so-called urban landscape" (Michalakeli, 2020). So, it becomes clear that choosing words to talk about a topic is a political act.

\section{Female homicides, spousal homicides and gender-based violence}

Gender-based violence can take many forms. Hidden forms of gender-based violence are difficult to 'diagnose'. Victims of homicide who turn to the police to speak may have fallen victim to psychological violence, but this is often not recognized, nor is it given the weight it should be. We mourn victims without bruises or obvious signs of abuse, but who could not work, could not leave the house, who were afraid to speak, who were afraid to look at their abuser. Gender-based violence can be silent. The purpose of this section is to make it clear and map out how gender-based violence is built. "According to the internationally recognized definitions of gender-based violence (GBVIMS), there are four basic types of gendered violence:

- sexual

- physical

- psychological

- financial.

It is worth noting, however, that local and national legal systems may define differently and / or have other legally recognized forms of gender-based violence (Gender Vased Violence). The forms of sexual violence are: verbal, physical, psychological / emotional abuse, rape, sexual violence, sexual harassment, human trafficking, sexual exploitation, financial violence, forced marriage, female genital mutilation, female genital mutilation. As Diotima ${ }^{1}$ characteristically states: "According to the largest poll conducted worldwide on violence against women (FRA, 2014), with the participation of over 42,000 women, aged 18 to 74, from 28 EU Member States :

- 1 in 3 women in the EU has been physically abused since the age of 15

- 1 in 2 women has experienced psychological violence from her partner

- 1 in 8 women have been financially abused by her partner

- 1 in 10 women has experienced sexual violence since the age of 15 or older

- 1 in 20 women has been raped

- 1 in 3 women has been sexually harassed in the workplace

- 1 in 5 young women, between 18-29 years old, has been sexually harassed online

- 1 in 5 women has experienced stalking

${ }^{1}$ https://diotima.org.gr/en/ 


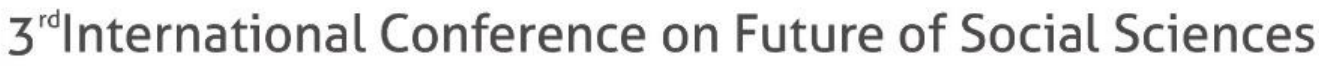

\section{5 - 7 March 2021}

- 50 women lose their lives every week due to domestic violence in the EU.

The Vienna Declaration on Female Homicide refers to ten forms of gender-based homicide (Artinopoulou, 2020):

- Murder of women as a result of domestic violence / domestic violence

- Torture and misogynistic murder of women

- Murder for reasons of honor

- Targeted killing of women and girls in the context of war conflicts

- Murder of women and girls for reasons related to the dowry

- For reasons of sexual orientation and sexual identity

- Murder of indigenous women and girls due to gender

- Female genital mutilation and illegal abortion due to the sex of the fetus

- Murder due to clitoridectomy

- Categories for magic

- Other murders related to gangs, organized crime, drug trafficking, human trafficking, weapons.

According to the General Secretariat for Gender Equality in the year 2016-2017, of the telephone calls he received, $85 \%$ concerned complaints of gender-based violence and $80 \%$ of them related to domestic violence with the perpetrator being the husband. ${ }^{2}$ According to Artinopoulou (2020): the common points of the definitions for female homicide include the following:

1. Gender discrimination as the background for committing homicides with women victims

2. Men exclusively as perpetrators of these crimes

3. The existence of intent on the part of the perpetrator to commit the crime.

Furthermore, $98 \%$ of abuse does not happen just once. ${ }^{3}$ In 2015 , a resolution was tabled in the European Parliament on genocide, which recognizes it and calls on the Commission to put forward concrete proposals to combat it. In Greece, however, there is no legal framework, nor is the murder of women recorded as such. This gap in itself is a brake on the way most people view homicide. The change in the legislation could change the way female homicide is treated in public discourse. Speaking of female homicide, the emergence of a gap emerges, which must be filled immediately, so that the perpetrators face the corresponding consequences. No form of psychological, physical, financial or sexual violence can be a family-private affair, as long as a person's life is at stake.

${ }^{2}$ https://www.youtube.com/channel/UCvLfv7T aTsRtpfkofSL8tQ

${ }^{3}$ https://www.iforinterview.com/ginaikoktonia-giati-prepeina-ksereis-afto-ton-oro/ 
Although many believe that violence is a feature of specific social groups, nationalities, social classes, etc., the reality shows that violence is not limited or determined by these parameters. "Violence against women... is a widespread phenomenon in all societies and all social classes, regardless of level of development, degree of political stability, culture or religion and is found in both public and private" (Gasuka, 2020). These researches - which map the character of the perpetrator - are important, as they prove that the person who commits gender-based violence does not have specific characteristics and may be the person next door. Instead of jeopardizing the character of the victims, it would be good to stand in the actions of the perpetrator and name them. Expressions such as 'why he did not speak', 'what he feared', 'since he knew who he was', 'he did not understand before' all they do are blame the victim, perpetuating gender-based violence and power relations.

\section{The coverage of the event in the media - The mapping of the perpetrator and the victim by the media}

The following cases of female homicide are indicative and present briefly the history of female genital mutilation and the comments about it that seem to be reproduced from site to site with few exceptions. The profile of the perpetrator is structured in a very specific way, as are the circumstances of death. It is therefore good to dwell on the details in order to highlight individual issues that seem to be ignored or seem to be omitted from these facts. The use of the Word is primarily a political act and is related to the wider socio-political context of action of individuals. Domestic violence is difficult to publicize and detect. Under the umbrella of private affairs, the violence experienced by women in the home is difficult to detect and is taboo for others to get involved as it is defined as 'personal issue', 'family affair', 'everyone does what they want at home' of etc. which suggests that it is a difficult to detect form of violence.

A murder took place in Trikala(2018), which is once again presented as a family tragedy. The wife worked as a nurse at the University Hospital of Larissa, while she was a candidate for local councilor of Gorgogiri in the last municipal elections. "According to neighbors, the murder took place in front of the children, their 14-year-old daughter and the 4year-old boy. The 14-year-old went out afterwards and asked for help. According to the neighbors, the husband's behavior was violent in the past, while one neighbor claimed that he had "saved" the victim in the past about six times.

"A family tragedy unfolded at noon in Megalochori, Trikala." More specifically, "a 50-year-old man slaughtered his wife in front of their children, after a fierce family quarrel".

"According to the testimonies of acquaintances and locals, the victim had taken precautionary measures a few days ago against her husband and murderer, as quarrels were frequent and ended in beatings."

"Specifically, the killer managed to stab the victim in the abdomen and in the ribs mainly, while there are knives in and in other parts of her body."

"According to the locals, the couple's fights have been very intense lately and as everything shows after a correspondingly intense fight, the 52-year-old killed his wife." 


\section{"Speaking to Epsilon TV, the man who lives next door revealed that he had saved the woman from her husband six more times."}

Homicide is presented as a family tragedy and a fierce family brawl. The victim was killed once again by a knife on various parts of his body. It is worth noting that a neighbor claimed that he saved her not once, but six times from the hands of her husband. What does this mean? That means that we are not talking about tragedy or accident, but about female homicide, as a result of gender-based violence and the conscious choice of the perpetrator to kill the victim. In addition, the neighbors seem to be aware of the frequent outbursts of the perpetrator, while the victim had taken action to ensure his safety. To achieve this, she took precautionary measures, which indicates that the extreme and violent behavior towards her had been repeated. The reason he appears to have killed his wife is about intense fighting, but in essence it is the ultimate form of gender-based violence. The fights were not the reason for the murder of the woman, but the belief of the perpetrator that he has a say in the body and life of the victim. The characterization of the perpetrator as a '50 year old man 'hides what he has done and in combination with the phrase' fierce family quarrel ', the victim is also involved in the incident. However, fighting is not an incentive to take someone's life. There is divorce, but the belief that his wife 'belongs' distorts the situation and hides the deeper causes of a social pathogenesis.

Another pattern that seems to be repeated is the pathological jealousy of a partner to police and take full control of his wife's life. The curious thing is that the perpetrator appears to claim that he had a reason for killing her, because he could not handle her as much as he wanted. The quarrel, which ended in a murder of a woman, started from the perpetrator's desire to put a bed bug in his wife's car, in order to keep an eye on her. The victim reacted and in response the perpetrator once again went out of his mind and shot her. The characteristics of the iceberg are also observed in this case. Strict control, frequent outbursts of anger and frequent physical violence inside and outside the home indicate that it is a homicide and not a 'bad moment', as he wants to present it.

"According to information, in the early hours of Sunday, the couple had a fight due to the 54-year-old's move to secretly put a bed bug in the 33-year-old's car."

"In some cases, the police were called as the 54-year-old systematically beat his wife, but nothing was ever done except for some remarks," said a neighbor of the couple.

The killer, according to his lawyer $\chi$, said he regretted his act, claiming that "he had a reason to lose control and shot his wife dead."

"The couple, especially in the first years of their marriage, had a lot of quarrels. "It was not a few times that the 54-year-old had beaten his wife even in the middle of the street with the neighbors separating them", said a neighbor of the couple ".

"Wearing a black hood, in an attempt to hide his facial features and speechless, the 54-year-old husband-killer appeared at the Heraklion Courthouse on Monday morning, who on Sunday confessed to shooting and killing his 33-year-old wife after a family affair"

"According to testimonies, the 54-year-old confessed perpetrator was pathologically jealous of his wife of 21 years, as a result of which they often had intense quarrels in the past, which led several times to violence by the 54-year-old." 
The perpetrator appears to feel bad about what he did, the journalist's reports on what he is wearing and how the 54-year-old is behaving want to show his bad psychological state. The perpetrator appears speechless and remorseful, while he is said to justify his action on the basis of the pathological jealousy he felt for the victim. Jealousy is presented as an excuse for the violence and intense quarrels he had with his wife. Pathological jealousy is related to imposing on the other and the desire for domination. The perpetrator killed the victim because he felt he could no longer control it, while the use of the words 'resulted' indicates that the perpetrator was acting out of jealousy, while presenting himself as a result of the perpetrator's unfavourable situation. The roles of perpetrator and victim seem to alternate, as the perpetrator declares himself a 'victim' of the jealousy he felt in order to justify his heinous behaviour. The reason according to the journalistic news is presented as jealousy and not gender-based violence. Once again, a female homicide murder is beautified on the basis of the pathological jealousy of the partner. However, jealousy is not a desire for control, enforcement and domination. The use of the term 'family' seems to embellish a situation of violence in which the perpetrator often seems to have engaged. Both the police and the neighbours seem to be aware of the perpetrator's violent behaviour, which was not limited to the private space of the house, but also took place in the public space. Are the recommendations of the police enough in such a situation? Clearly not as such cases of victims of gender-based violence remain exposed and at any time can lose their lives as was the case in this case of female homicide.

\subsection{Why don't you report him? Capturing opinions}

In 2020, a very important action took place in Thessaloniki, which summarizes the reasons why many women do not report gender-based violence. The event took place on November 25, International Day for the Elimination of Violence against Women. This activist action wanted to present in the most brilliant and understandable way the fears that follow the victim. This is how the fight against victim blaming is attempted, where even in extreme cases of abuse no one wonders why the perpetrator behaved like that, but what the victim did and caused.

\section{"I COMPLAINED HIM BUT:}

- the judge asked me if I had drunk, if I was moving slowly, if I was wearing red lace.

- the media they mocked me, they humiliated me.

- I had to change my place of residence after relatives and friends avoided me.

- the police advised me to go back to my husband, not to break up my family.

- continued to harass and threaten me in front of our children violating the restrictive terms.

- hid behind the anonymity of the internet.

- I do not know how we will live because I have no income.

- with his connections and his best salary he managed to present me as an inadequate mother and take care of our children even though he abused me for many years. 


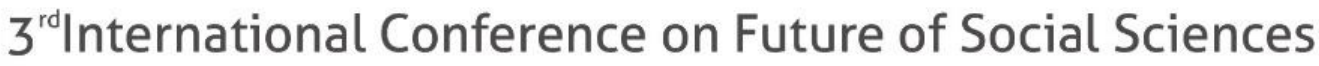

\section{5 - 7 March 2021}

- he killed me in front of my children because I refused to go back.

- they did not believe me when I said that my father is my rapist.

- they did not believe that the priest raped me.

- my teachers at school said that the way I dress arouses my classmates.

- I will spit blood to get a degree because the teaching establishment supports him.

- I was told that my own delinquency was to blame for the degrading behavior of the police during my detention at the police station or prison.

- with the power of the employer and without a union to support me, he fired me and took care not to find a job in the industry again.

- it was never found who attacked me with murderous intentions because I claimed not to be exploited so brutally as workers.

The above are snippets from the experience of the few women who found the courage to complain or try to get away from relationships that ruin their lives at home, at work, at school or at school, in public services, in the public space. It is easy to understand why their experience works as a deterrent to the rest "4

\section{Conclusion}

In view of all these incidents, it is time to re-raise issues that are considered by many to be 'resolved' within the Western world. But is that so? Clearly not, the ability and access to resources - electronic and non-electronic - have given access to the 'private' space. The shift to privacy has brought to the surface 'private' issues such as domestic violence, marital rape, etc., which are not only 'private'. These behaviours are not limited to the private space and when a door closes one has to think about what is happening behind the scenes. It is not a family tragedy, it is not a crime of passion, it is not a crime of jealousy, it is not a simple quarrel, it is a homicide, it is done intentionally and the perpetrator's desire to kill, abuse and level the other has been repeated because he can! "It needs to be understood that it is not just a personal problem of someone / viruses, but a social problem and we need to discuss for equality again" (Vagena, 2020). According to Gasuka (2020), on the basis of the triptych ResearchPrevention-Action should be done immediately:

- Production of tools and research methodologies-conducting valid research, data acquisition

4 https://thepressproject.gr/giati-den-katangelleis-to-thyma-den-borei-na-ta-kataferei-mono-toumia-katangelia-denarkei/?fbclid=IwAR3BVn12KTrt6qFVTpAKBbJE5vvY_t8HICRGCw0VrAOQ8Kd1ytsQC5XRBxE\# X8FUsi5R0Ss.facebook 
- Acceptance of the term feminicide and its inclusion in the legal system, as a hate crime with sexist motives

- Documentation of the victim-perpetrator relationship

- Creation of models for the investigation and interpretation of female homicide

- Thorough control that takes into account the gender of each case of murder of a woman

- Wide relevant social awareness at local, national and international level

- Education / awareness of social groups involved in the phenomenon

- Legislation prohibiting the possession and use of firearms

- Punishment of government agencies that are negligent in dealing with the problem and / or push the victim to return to the perpetrator

- Complete and integrated security system of citizens, women and men.

"Enhancing visibility and breaking the silence at the level of procedures and institutions, first of all, concerns the acceptance by the state of social groups, institutions, civil society, the media, etc., that genocide is a social phenomenon and given the life of women, which must be researched, not only in the context of feminist theory and approach, but interdisciplinary as a distinct and scientifically acceptable object" (Vougiouka, 2020). Also, the management of incidents of gender-based violence must be dealt with more effectively by the state and its authorized bodies, but also by the wider society, neighbours, acquaintances, passers-by, etc. Awareness of such phenomena and the successful and timely response to incidents of genderbased violence can save these women. If you hear something, talk, inform and motivate others to do the same. Violence, no matter where it comes from, is not a private matter, it is a deeply social problem that must be addressed in order to prevent future homicides. It is good to stand at the base of the iceberg and the way gender-based violence is built, because when one reaches the top of the iceberg it is already too late.

Another issue worth dwelling on is the responsibility of a situation and how it is shifted by the media. In cases of domestic violence, the responsibility for what happens is often transferred to the victim and not to the perpetrator. Expressions such as:

- well, why doesn't she leave?

- what is still waiting? Kill her?

- are they idiots?

- say poor thing!

- why does she not do something for her children?

- she is a victim!

- after tolerating them well to suffer!

all they do is shift the responsibility from the abuser to the victim. The same goes for raping a woman. The sexuality, the love life of the victim and the clothes she wears are used by the journalistic discourse in such a way that a form of consensus is cultivated as to what he suffered and experienced. The shift of responsibility is cultivated with sexist comments, allusions and exposure. In most cases we see the face of the victim everywhere and never or rarely the face of the perpetrator. A very specific approach to one situation is structured, 
cultivated and built at a time. We see that sexism is reproduced even in such cases. Instead of blaming the victim in any case of financial, psychological, physical and sexual violence, the responsibility should be shifted to the perpetrator and his actions. Society and the state themselves must take over the situation and create the conditions so that these women can leave in time and build a new and safe life.

\section{References}

Artinopoulou, B. (2020). Female homicide: Conceptual and methodological issues In G. Petraki (ed.) Female homicide: findings, questions and question marks. Athens: Gutenberg, pp. 32-41

Vagena, S. (2020). So what is the role of the Greek police in the issue of Female homicide? In G. Petraki (ed.) Female homicide: findings, questions and question marks. Athens: Gutenberg, pp.112-117

Vougiouka, A. (2020). Homicide: International experience, political discrimination and the transformation of silence into speech and action In G. Petraki (ed.) Female homicide: findings, questions and question marks. Athens: Gutenberg, pp.73-86

Gasuka, M. (2020). Old history in modern contexts: Feminicide / Female homicide In G. Petraki (ed.) Female homicide: findings, questions and question marks. Athens: Gutenberg, pp. 55-69

Echo, O. (1994). Theory of semiotics, E. Kallifatidis (trans.). Athens: Gnosi Publications

Kalfa, M. (2017). Propagating the truth: the media and the economic crisis In Ch. Konstantopoulou (ed.). Crisis narratives: Myths and realities of modern society. Athens: Papazisis Publications, pp. 79-86

Laqueur, T. (2003). Constructing gender: Body and social gender from the ancient Greeks to Freud. Athens: Polytropon Publications

Michalakeli, A. (2020). Female homicide in public discourse and the public sphere In G. Petraki (ed.) Female homicide: findings, questions and question marks. Athens: Gutenberg, pp. 87-96

Pavlidou Theodosia-Soula. (2006). Language-gender-gender: Problems, Searches and Greek Language in TH.S. Pavlidou (ed.), Language-Gender-Gender, Thessaloniki: Institute of Modern Greek Studies, pp. 15-63

Petraki, G. (2020). Murders are invisible murders In G. Petraki (ed.) Murders: findings, questions and question marks. Athens: Gutenberg, pp. 19-31

Tsitsanoudi-Mallidi, N. (2006). The popular language of the news: An attitude of deceptive intimacy. Athens: Experience Editorial

Tsitsanoudi-Mallidi, N. (2008). The subject and the victim: Language, Education and Mass Media. Athens: Experience Editorial

Fragoudaki, A. (1988). Latent language: Eva's daughter and the predominant genus In Dini.3, pp. 82-85 